\title{
Dünnschichtsensor für hochaufgelöste Dickenmessung
}

$M$ it dem Dünnschichtsensor FTR hat die Firma Fries Research \& Technology jetzt ein optisches Dünnschichtreflektometer für die Dickenmessung transparenter dünner Schichten und Schichtsysteme auf den Markt gebracht. Das reflektometrische Verfahren zeichnet sich durch eine berührungslose, zerstörungsfreie Messung mit hoher Auflösung aus. Damit ist es besonders für den Einsatz an sensiblen Materialien der Halbleiter-, MEMS- und Solartechnik wie zum Beispiel Oxiden, Nitriden, Fotolack und anderen optisch transparenten Schichten geeignet. Messungen lassen sich in Kombination mit den Messgeräten des Herstellers wie etwa dem

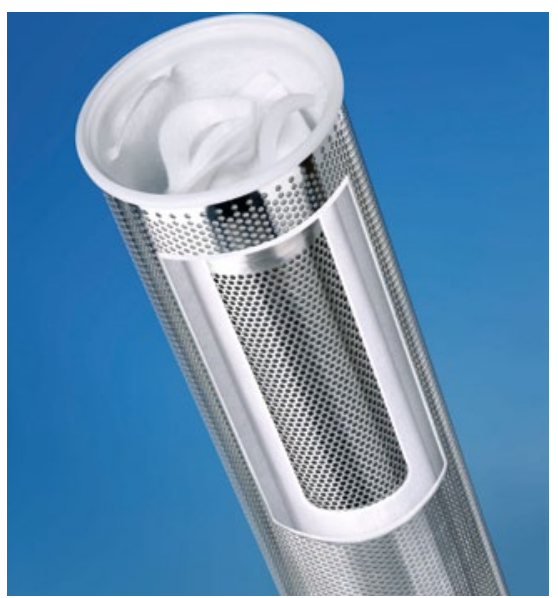

MicroProf 200 durchführen. Der Dünnschichtsensor arbeitet mit einer spektral aufgelösten Reflexionsmessung und einer hochentwickelten Auswertesoftware. Die Schichtdickenmessung beruht auf der Überlagerung von Teilwellen, die an den Grenzflächen des dünnen Films reflektiert werden. Die Auswertung dieses spektralen Interferenzmusters mit der speziell für dieses Gerät entwickelten Software liefert Schichtdickeninformationen in Nanometerauflösung. Die Ergebnisse werden erfasst, ausgewertet und visualisiert. Zum Sensor gehört auch eine umfangreiche Datenbank mit den Brechungs- und Absorptionsindizes einer Vielzahl von Materialien. Für die automatisierte Messung (punktuell, Linienprofil oder 3D-Mapping) können Rezepte zusammengestellt werden. Das Gerät erreicht eine hohe Mess- und Wiederholgenauigkeit.

Tel. 02204 84-2430, www.frt-gmbh.com

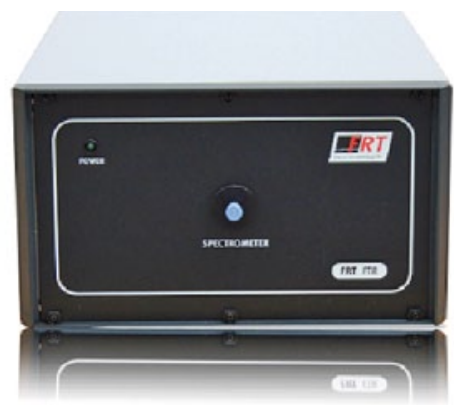

\section{Neues Filtrationssystem reduziert Betriebskosten}

$\mathrm{D}$ as neue Hayflow-Filtrationssystem von Eaton Technologies vereint die Eigenschaften von Filterbeutel und Filterkerze zu einem neuen Filterelement, das optimale Filtrationseigenschaften bietet. Die Oberfläche des Hayflow-Elements ist bis zu $65 \%$ größer als ein vergleichbarer Filterbeutel. Dadurch bedingte längere Standzeiten und geringe Wechselintervalle führen zu niedrigeren Betriebskosten. Bis zu fünffach höher sind die Standzeiten ge- genüber herkömmlichen Filterbeuteln. Hohe Durchflussmengen ermöglichen bei der Planung von Filtrationssystemen eine Reduzierung der Filterkesselgrößen um bis zu 50\%. Im Vergleich zu Standardfilterkerzen ist das neue Filtrationssystem um bis zu 35-mal effektiver. Die neuen Filterelemente lassen sich einfach in vorhandene Filtergehäuse einsetzen und sorgen für eine kostengünstige Wartung.

Tel. 02486809 400, www.eaton.com/filtration

\section{Schutzbrillen-Beschichtung verlängert Gebrauchsdauer}

J e nach Arbeitsumfeld sind Schutzbrillen extremen Belastungen ausgesetzt. Die Folge: Kratzer auf der Scheibe. Die neue RAS-Beschichtung (RAS = Robuste Antikratz) von 3M sorgt für eine 5-mal längere Kratzbeständigkeit als andere 3M-AntikratzBeschichtungen. Zwei Modelle der 3M-Maxim-Serie wurden nun erstmals damit ausgestattet. Beide Schutzbrillen mit RAS-Beschichtung lassen sich individuell an die Kopf- und Gesichtsform des Trägers anpassen. So sorgt die Schutzbrille dank längenverstellbaren Bügeln und einer individuell anpassbaren Scheibenneigung für einen optimalen Sitz. Die Schutzbrille 3M Maxim Ballistic verfügt über kurze, flache Bügel und eignet sich deshalb besonders zur Kombination mit Kapselgehörschutz. Die weichen Bügelenden garantieren ein angenehmes Tragegefühl. Alle Schutzbrillen der Maxim-Serie sind mit biegsamen, einstellbaren Nasenpads und einem "Soft-touch" Augenbrauenschutz ausgestattet. Die asphärischen Scheiben bieten eine perfekte, verzerrungsfreie 180 Grad Sicht.

www.3Marbeitsschutz.de

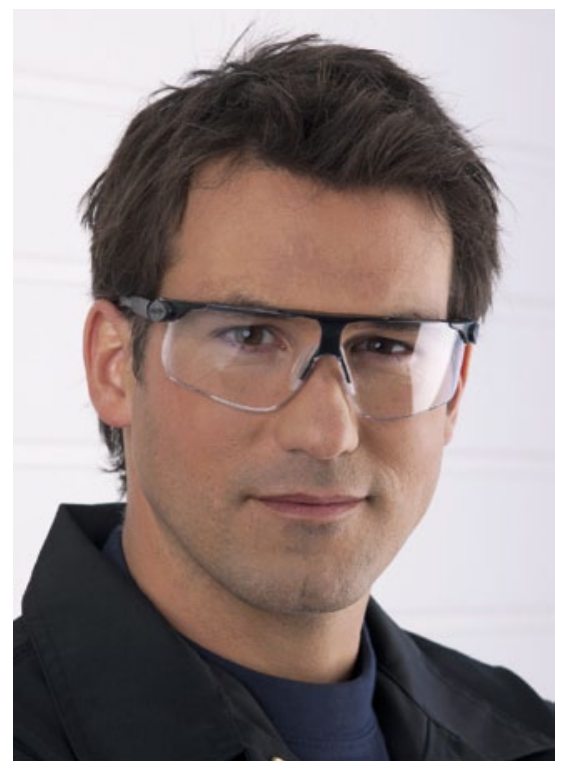

